\title{
Über die oxydierende Wirkung des Hydroxylamins.
}

\author{
Von \\ L. Marino.
}

In dem Protokoll der russischen chemischen Gesellschaft (4. Februar 1899) ist angegeben, dals TanataR Ammoniumsulfat durch Einwirkung des chlorwasserstoffsauren Hydroxylamins auf eine Lösung schwefliger Säure erhält. In dem „Bericht deutsch. chemischer Gesellschaft 32, 241" beschreibt TANATAR seine darüber angestellten Versuche, und im folgenden Hefte spricht Raschio die Meinung aus, dals das von Tanatar erhaltene Salz nicht Ammoniumsulfat sei, sondern Amidosulfonsäure, und dafs es sich deshalb nicht um eine Oxydation, sondern um eine glatte Kondensation der schwefligen Säure handele.

Da es aber nach dem, was Raschig über die Arbeit von Tanatan sagt, scheint, dafs er im Glauben ist, dieser sei der erste gewesen. der die anorganischen Oxydationsreaktionen des Hydroxylamins beschrieben hat, sei es mir erlaubt, zu erinnern, dals Prof. Piccini schon im Jahre $1895^{1}$ bewiesen hat, dafs Hydroxylamin in Schwefelsäurelösung das $\mathrm{V}_{2} \mathrm{O}_{3}$ in $\mathrm{V}_{2} \mathrm{O}_{4}$ umwandelt, und sich vorbehalten hat, das vollständige Studium ähnlicher Oxydationsreaktionen zu unternehmen, mit denen ich mich auf seinen Rat seit einiger Zeit beschäftige. Und da ich schon habe feststellen können, dals mehrere niedrigere Oxyde der Metalle und Nichtmetalle durch Hydroxylamin in höhere Oxyde umgewandelt werden, behalte ich mir vor, meine Versuche zu beschreiben, wenn sie vervollständigt sein werden.

Es sei hier nur erwähnt, dals ich bei der Einwirkung von Hydroxylamin auf schweflige Säure, in Übereinstimmung mit dem Resultate von RAschic, aus der mit Barytwasser behandelten Flüssigkeit das Baryumsalz der Amidosulfonsäure in seideglänzenden Nadeln erhalten habe.

1 Orosi (1895) 18, 258-259; Z. anorg. Chem. (1896) 11, 111; Gax: chim. (1895) [2] 25, 456; Ber. deutsch. chem. Ges. 29, 271 (Referat). Es ist zu bemerken, dafs, durch ein Versehen, in der „Zeitschr. f. anorg. Chem.“ der Satz fehlt, doch ist dies übrigens leicht ersichtlich, da der quantitative Beweis dieser Reaktion angefuhrt ist.

Florenz, Pharm.-chem. Laborat. des Istituto di Studi Superiori.

Bei der Redaktion eingegangen am 9. April 1899. 